ORIGINAL ARTICLE

\title{
Intra-articular Injections of Cross-linked Hyaluronic Acid in Japanese Patients with Symptomatic Osteoarthritis of the Hip
}

\author{
Gaku Koyano MD, PhD ${ }^{\text {a,b }}$ Tetsuya Jinno MD, PhD ${ }^{\text {a,b }}$ Daisuke Koga MD, PhD ${ }^{\text {a,c }}$ \\ Chisato Hoshino MD, PhD ${ }^{\text {a }}$ and Atsushi Okawa MD, PhD ${ }^{a}$
}

\begin{abstract}
Objectives: We investigated the efficacy and safety of Hylan G-F 20 for the treatment of hip osteoarthritis in Japanese patients. Methods: Twenty-nine patients with hip osteoarthritis (OA) received Hylan G-F 20 injection into the hip. The visual analog scale of pain during gait (VAS-G), VAS of pain at rest, hip joint function evaluated by the Japanese Orthopaedic Association (JOA) score, health-related quality of life (HRQoL), and adverse events were evaluated before, immediately after, and at 4,8 , and 12 weeks after injection. Patients were categorized according to the severity of OA (mild and severe OA groups) and dysplasia (dysplastic and non-dysplastic groups) and these groups were compared. Results: After the injection, VAS-G improved significantly for 12 weeks. VAS-G was lower (less pain) in the mild OA group than in the severe OA group at each time point. There were no differences in VAS-G between the dysplastic and non-dysplastic groups throughout the observation period. VAS-G improved significantly in the dysplastic group after the injection. The JOA score and HRQoL demonstrated the same tendency as VAS-G. Three patients experienced worsening of local pain immediately after the injection; however, the pain on the following day was less than that before the injection in all three hips. Conclusions: Hylan G-F 20 injection into the hip joint was effective in reducing hip pain and can be used as a non-operative treatment option for hip OA in the Japanese population.
\end{abstract}

Key Words: dysplasia; non-operative treatment; Hylan G-F 20; viscosupplementation; pain

\section{INTRODUCTION}

Osteoarthritis (OA) of the hip joint is a relatively common progressive degenerative joint disease. It involves the slow deterioration of the joint with a gradual increase in pain and loss of function and ability to perform the activities of daily living. ${ }^{1)}$ In Japan, the major cause of hip OA is acetabular dysplasia. ${ }^{2)}$ The onset of pain occurs in younger patients with dysplastic hips than in those with non-dysplastic hips. ${ }^{2}$ Younger patients tend to choose non-operative treatment owing to the limited durability of hip implants. In some younger patients, parenting, parental care, and work are prioritized, and conservative treatments are chosen rather than surgery. In such cases, non-operative treatment of younger patients aims to prolong the time to operative therapy.

For non-operative treatment, oral agents, physical therapy, and intra-articular injection (IA) are commonly used. Oral agents such as acetaminophen or non-steroidal anti-inflammatory drugs (NSAIDs) are useful for pain relief and improvement in daily activities. However, oral NSAIDs are not a satisfactory treatment because long-term use may cause adverse events and may accelerate the progression of

Received: April 16, 2021, Accepted: August 25, 2021, Published online: September 29, 2021

${ }^{a}$ Department of Orthopaedic Surgery, Medical Hospital of Tokyo Medical and Dental University, Tokyo, Japan

bepartment of Orthopaedic Surgery, Dokkyo Medical University Saitama Medical Center, Saitama, Japan

'Department of Orthopaedic Surgery, Saitama Red Cross Hospital, Saitama, Japan

Correspondence: Tetsuya Jinno, MD, PhD, Department of Orthopaedic Surgery, Dokkyo Medical University Saitama Medical Center,

2-1-50 Minami-Koshigaya, Koshigaya, Saitama 343-8555, Japan, E-mail: jinnot@dokkyomed.ac.jp

Copyright (C) 2021 The Japanese Association of Rehabilitation Medicine

This is an open-access article distributed under the terms of the Creative Commons Attribution Non-Commercial No

Derivatives (CC BY-NC-ND) 4.0 License. http://creativecommons.org/licenses/by-nc-nd/4.0/ 
hip joint disease. ${ }^{3)}$ Physical therapy such as muscle exercise and stretching is effective in reducing pain and dysfunction in the short-term ${ }^{1)}$; however, its long-term effect on preventing OA progression is unknown.

For IA therapy, local anesthetic drugs, corticosteroids, and hyaluronic acids (HA) are used. Local anesthetics are effective for a short duration only, and may be cytotoxic ${ }^{4)}$; therefore, their use alone is questionable. IA of steroids may also provide short-term pain relief and reduce dysfunction; however, the long-term effects are unknown, and there is a concern about septic arthritis. ${ }^{5)}$ Therefore, IA of steroids cannot be used repeatedly.

In OA joints, the rheological properties of the synovial fluid have deteriorated owing to a decrease in HA concentration and a reduction in the molecular weight of HA compared with healthy joints. ${ }^{6}$ ) IA of HA (IA-HA) improves the rheological properties of the synovial fluid of the OA joint and restores its lubricating and shock-absorbing properties. IA-HA has been widely used for the treatment of knee OA. The strength of recommendation of IA-HA for OA knees in the Osteoarthritis Research Society International 2019 guidelines was $60-74 \%$ (Level 2) $)^{7}$; in contrast, that in the Japanese guidelines was $87 \%{ }^{8}$ ) The American Academy of Orthopaedic Surgeons guidelines do not recommend the use of IA-HA to the knee. ${ }^{9)}$ This inconsistency in the strength of recommendations among the international guidelines may result from differences in the indications in Japan and those in European countries and the United States. ${ }^{8)}$ IA-HA for knee OA is applied only in advanced cases in Europe and the United States, whereas it is used from the early stages of disease in Japan, and therefore the effects obtained may be different in different countries. ${ }^{8)}$

For hip OA, several studies have reported that pain is reduced in the short-term by IA-HA, and function disability is improved. ${ }^{10-16)}$ These reports are from Europe and the United States, because the use of HA for hip OA is not covered by insurance in Japan and is therefore rarely used. Hylan G-F 20 is a cross-linked sodium hyaluronate with a high average molecular weight of 6 million Dalton. ${ }^{17)}$ It has been used in IA for hip OA in Europe and the United States, but not in Japan, and, therefore, there are no data available in the literature on the clinical benefits of such viscosupplementation for hip OA in the Japanese population. Most Japanese OA patients have secondary OA resulting from hip dysplasia, ${ }^{2)}$ and the type of $\mathrm{OA}$ is therefore different from that most commonly seen in Europe and the United States. As discussed above, different degrees of recommendation are given for IA-HA owing to differences in indications and/or characteristics of OA in dif- ferent counties; therefore, it is necessary to provide evidence according to the indications applied in each country. We conducted a prospective case-series study to investigate the efficacy and safety of Hylan G-F 20 for the treatment of hip OA in Japanese patients.

\section{MATERIALS AND METHODS}

Thirty patients with hip OA were recruited for this study. The required sample size was calculated to be 20 by a priori power analysis for paired $t$-tests using parameters with an effect size of 0.67 (difference of average 10, standard deviation 15), an alpha error of 0.05 , and a beta error of 0.20 . The inclusion criteria were: (1) patients diagnosed with OA of the hip joint by plain radiographs, (2) outpatients who can walk, (3) patients aged 20-84 years, ${ }^{2,18)}$ and (4) patients who submitted the consent form for this study. The exclusion criteria were: (1) patients lacking the ability to agree or to express agreement appropriately for participation in this study; (2) pregnancy or the possibility of pregnancy; (3) patients breastfeeding children; (4) patients with hypersensitivity to HA, avian protein, feathers, or eggs; (5) patients with stagnation of venous blood or lymph in lower limbs at the injection site; (6) patients with serious liver damage or a medical history of serious liver damage; (7) patients with skin disease or infection around the injection area; (8) patients with serious comorbidities (heart disorder, renal disease, malignant tumor, or compromised host such as immunodeficiency); and (9) patients judged unsuitable by the attending doctor. All patients provided written informed consent before inclusion.

Anteroposterior (AP) radiographs taken with the subject in the supine position and Lauenstein 1 radiographs of the hip joint were obtained. The radiographic severity of hip OA was classified into four stages (i.e., pre-OA and initial, advanced, and terminal stages) according to the guidelines of the Japanese Orthopaedic Association. ${ }^{18,19)}$ We divided these severities into two groups, i.e., a mild OA group (pre and initial OA) and a severe OA group (advanced and terminal $\mathrm{OA}$ ), which correspond to grades $0-2$ and 3-4, respectively, of the Kellgren and Lawrence system for classification of OA. The center-edge angle (CE angle) was evaluated using AP radiographs of the hip. ${ }^{20)}$ Hips with a CE angle less than $20^{\circ}$ were defined as dysplastic hips.

Single intra-articular preparation of $2 \mathrm{ml}$ of Hylan G-F 20 (Synvisc ${ }^{\circledR}$; Sanofi K.K., Tokyo, Japan) was injected into each patient's affected hip in an out-patient setting after confirmation of the needle position using an air arthrogram ${ }^{21)}$; arthrocentesis was performed before the injection, when feasible. 
After the injection, patients were allowed to resume normal activities and to continue any routine conservative therapies such as oral analgesics and physiotherapy. All patients were followed up at 4, 8, and 12 weeks after the injection. After completion of the 12-week evaluation, a second injection was performed if the patient requested it.

The primary endpoint was the severity of hip pain during gait (VAS-G) and at rest (VAS-R) evaluated at each visit by $0-100 \mathrm{~mm}$ visual analog scale scores $(0$ and 100 represent "no pain" and "the worst pain imaginable," respectively). ${ }^{22}$ Secondary endpoints were pain provocation test results for hip osteoarthritis (the number of patients with three or more positive signs on pain provocation tests), hip joint function evaluated using the Japanese Orthopaedic Association scoring system (JOA score), ${ }^{2,23}$ and health-related quality of life (HRQoL) evaluated using the EuroQol-5D (EQ-5D) questionnaire. Adverse events were recorded on the day of the injection and at each follow-up visit. If adverse events were suspected between visits, patients were advised to visit earlier or to consult by phone. The results at each time point after the injection were compared with those before the injection. After the optional second injection, VAS, JOA score, and HRQoL were evaluated at 4, 8, and 12 weeks.

Four pain provocation tests ${ }^{24,25)}$ for hip pathologies were applied to patients at each visit (before, immediately after, and at 4,8 , and 12 weeks after the injection). The flexion, abduction, and external rotation (FABER) test ${ }^{24}$ ) was performed by moving the hip joint in flexion, abduction, and external rotation with the knee flexed (figure-of-four position); the test was regarded as being positive if groin or buttock pain was evident. In the flexion, adduction, and internal rotation (FADIR) test ${ }^{24)}$ the hip joint was passively flexed, adducted, and internally rotated, and judged positive if groin or buttock pain resulted. The resistive straight leg raising (rSLR) tes $\mathrm{t}^{24}$ ) was conducted in the manner described below. The hip joint was actively flexed to approximately $30^{\circ}$ with the knee extended and the subject in the supine position; the examiner applied pressure on the lower extremity just above the knee toward the examination table. The result was regarded as positive if groin or buttock pain occurred. Tenderness at Scarpa's triangle ${ }^{25)}$ was also recorded. Patients were categorized into two groups: those with three or more positive pain provocation tests results and those with less than three.

The clinical score of the hip joints was assessed using the JOA score. ${ }^{22,23)}$ The JOA scoring system is composed of four categories: pain (0-40 points), range of motion (ROM: flexion/extension and abduction/adduction [0-20 points]), walking ability ( $0-20$ points), and activities of daily living ( $0-20$ points). A total score of 100 indicates maximum hip function. Quality of life was assessed by the HRQoL score at each visit. All patients were interviewed using the EQ-5D questionnaire. The Japanese version of the HRQoL score was used and scores were calculated as described in the literature. ${ }^{26)}$

Changes in VAS scores and HRQoL scores during the study period were analyzed using repeated-measures analysis of variance (ANOVA). Before the ANOVA, the normal distribution of the data was confirmed using the Kolmogorov-Smirnov test, and the sphericity was checked using Mauchly's test. The sphericity criteria were not fulfilled in all cases, and so the Huynh-Feldt correction was applied. To elucidate the influence of OA severity, ANOVA was also applied to compare the differences in VAS scores and HRQoL scores between the mild and severe OA groups. Similarly, the differences between dysplastic and non-dysplastic hip groups were analyzed using ANOVA. A paired $t$-test was applied for continuous variables to compare the averages pre- and post-injection. The number of patients positive on each pain provocation test and the number with a minimum of three positive signs of pain on provocation tests were analyzed using the McNemar method. The time courses of JOA scores were analyzed using the Wilcoxon rank-sum method. Comparisons of JOA scores between the mild and severe OA groups and between the dysplastic and non-dysplastic groups were performed using the Mann-Whitney method. All statistical analyses were performed with R using EZR ( $R$ commander with statistical functions added), ${ }^{27}$ and $\mathrm{P}<0.05$ was considered significant. The Bonferroni correction for multiple comparisons was utilized; P-values of VAS scores and pain provocation test results were quadrupled, and those of JOA scores and HRQoL scores were tripled.

This study was approved by the institutional review board and registered on the University Hospital Medical Information Network Clinical Trials Registry (Registration number: UMIN000018000).

\section{RESULTS}

Among the 30 patients ( 3 men and 27 women) recruited, one female patient was excluded because of loss to follow-up after 4 weeks. Another female patient could not report to the hospital 12 weeks after the injection due to a high fever. The remaining 28 patients completed 12 weeks of follow-up. Thus, 29 cases were included in the analyses of data obtained pre-injection, immediately after, and at 4 and 8 weeks after 
Table 1. Patient demographics

\begin{tabular}{|c|c|c|c|c|c|c|c|}
\hline & $\begin{array}{c}\text { All cases } \\
n=29\end{array}$ & $\begin{array}{c}\text { Mild OA } \\
n=9\end{array}$ & $\begin{array}{c}\text { Severe OA } \\
n=20\end{array}$ & P-value ${ }^{1)}$ & $\begin{array}{c}\mathrm{CE}<20^{\circ} \\
\mathrm{n}=19\end{array}$ & $\begin{array}{c}\mathrm{CE} \geq 20^{\circ} \\
\mathrm{n}=10\end{array}$ & P-value ${ }^{2)}$ \\
\hline Age/years & $\begin{array}{c}58.4 \pm 10.9 \\
(37-79)\end{array}$ & $\begin{array}{c}52.7 \pm 12.0 \\
(37-68)\end{array}$ & $\begin{array}{c}61.0 \pm 9.6 \\
(45-79)\end{array}$ & 0.056 & $\begin{array}{c}57.6 \pm 10.6 \\
(37-77)\end{array}$ & $\begin{array}{c}63.8 \pm 10.0 \\
(43-79)\end{array}$ & 0.604 \\
\hline Male/Female & $3 / 26$ & $1 / 8$ & $2 / 18$ & 1.000 & $1 / 18$ & $2 / 8$ & 0.267 \\
\hline Height $/ \mathrm{cm}$ & $\begin{array}{c}156.1 \pm 5.9 \\
(142-171)\end{array}$ & $\begin{array}{c}158.6 \pm 3.4 \\
(154-164)\end{array}$ & $\begin{array}{c}155.0 \pm 6.5 \\
(142-171)\end{array}$ & 0.130 & $\begin{array}{c}155.7 \pm 5.8 \\
(142-166)\end{array}$ & $\begin{array}{c}154.4 \pm 3.6 \\
(150-160)\end{array}$ & 0.645 \\
\hline Body weight $/ \mathrm{kg}$ & $\begin{array}{c}52.8 \pm 5.4 \\
(40-66)\end{array}$ & $\begin{array}{c}53.5 \pm 3.3 \\
(49-57)\end{array}$ & $\begin{array}{c}52.5 \pm 6.2 \\
(40-60)\end{array}$ & 0.634 & $\begin{array}{c}53.4 \pm 6.2 \\
(40-66)\end{array}$ & $\begin{array}{c}51.1 \pm 2.9 \\
(49-56)\end{array}$ & 0.381 \\
\hline $\mathrm{BMI} / \mathrm{kg} / \mathrm{m}^{2}$ & $\begin{array}{l}21.7 \pm 2.2 \\
(17.1-27.1)\end{array}$ & $\begin{array}{c}21.3 \pm 1.3 \\
(19.1-22.9)\end{array}$ & $\begin{array}{l}21.9 \pm 2.5 \\
(17.1-27.1)\end{array}$ & 0.512 & $\begin{array}{l}22.0 \pm 2.2 \\
(18.4-27.1)\end{array}$ & $\begin{array}{c}21.5 \pm 1.6 \\
(19.1-23.6)\end{array}$ & 0.258 \\
\hline $\begin{array}{l}\text { Injection side } \\
\text { Right/Left }\end{array}$ & $18 / 11$ & $6 / 3$ & $12 / 8$ & 1.000 & $11 / 8$ & $7 / 3$ & 0.694 \\
\hline $\mathrm{CE}$ angle $/^{\circ}$ & $\begin{array}{c}19.3 \pm 15.1 \\
(-6.3 \text { to } 55.0)\end{array}$ & $\begin{array}{c}22.6 \pm 10.7 \\
(5.5-34.3)\end{array}$ & $\begin{array}{c}17.8 \pm 16.7 \\
(-6.3 \text { to } 55.0)\end{array}$ & 0.441 & $\begin{array}{c}10.3 \pm 6.8 \\
(-6.3 \text { to } 19.0)\end{array}$ & $\begin{array}{l}36.4 \pm 10.8 \\
(21.1-50.0)\end{array}$ & $<0.001^{*}$ \\
\hline
\end{tabular}

OA, osteoarthritis; CE, center-edge angle; BMI, body mass index.

Figures in parentheses are the range of each parameter.

${ }^{1} \mathrm{P}$-values calculated for comparison between the mild and severe OA groups.

${ }^{2} \mathrm{P}$-values calculated for comparison between patients with CE angle less than $20^{\circ}$ (dysplastic hips) and more than $20^{\circ}$.

*Significant.

injection, and 28 cases were included for analyses of data obtained between pre-injection and 12 weeks after injection. Patient demographics for all 29 subjects are summarized in Table 1. In total, 8 hips had a diagnosis of primary osteoarthritis, 19 had dysplastic osteoarthritis, 1 had OA due to idiopathic osteonecrosis of the femoral head, and 1 had OA due to trauma. Nine hips were classified as initial stage OA, 7 were in the advanced stage, and 13 were in the terminal stage. The radiographic severities of the non-injected sides were pre-osteoarthritis, 20; initial stage, 7; and advanced stage, 1. One hip on the non-injected side had previously undergone arthroplasty. The average age was higher in the severe OA group than in the mild OA group; however, the difference was not statistically significant. There was no statistical difference in sex, height, body weight, BMI, injection side, or CE angle between the mild and severe OA groups. When the demographics were analyzed in terms of the dysplastic and non-dysplastic groups, there was no statistical difference between the groups in any parameter other than the $\mathrm{CE}$ angle.

Changes in VAS-G after injection are summarized in Fig. 1 VAS-G improved after injection ( $\mathrm{P}<0.001$, ANOVA), suggesting that Hylan G-F 20 is effective in decreasing pain during gait. Pairwise analysis demonstrated that VAS-G decreased immediately after the injection and remained low during the observation period compared with that before injection.
Comparison of VAS-G scores between the mild and severe OA groups at each time point demonstrated that the pain score during gait was lower in the mild OA group than in the severe OA group; however, the difference was not statistically significant immediately after injection or at 8 weeks after injection. VAS-G improved after injection in both the mild $(\mathrm{P}=0.010)$ and severe OA groups $(\mathrm{P}<0.001)$, and there was no time $\times$ group interaction $(\mathrm{P}=0.341)$. A paired $t$-test also showed that VAS-G improved for the entire 12week follow-up period in both groups; however, statistical significance was not achieved immediately after or at 8 and 12 weeks after injection in the mild OA group.

There was no difference in VAS-G between the dysplastic and non-dysplastic groups at any time point. VAS-G improved after injection in the dysplastic group ( $\mathrm{P}<0.001$ ); however, statistical significance was not observed in the non-dysplastic group $(\mathrm{P}=0.077)$. There was no time $\times$ group interaction $(\mathrm{P}=0.603)$. A paired $t$-test also demonstrated that VAS-G improved throughout the 12-week follow-up period in both groups; however, statistical significance was not observed immediately after or at 8 and 12 weeks after injection in the non-dysplastic group.

ANOVA showed that VAS-R improved significantly after injection, as illustrated in Fig. 2; however, pairwise analysis demonstrated that the effect wore off between 4 and 8 weeks post-injection.

There was no difference in VAS-R scores between the mild 
(A)

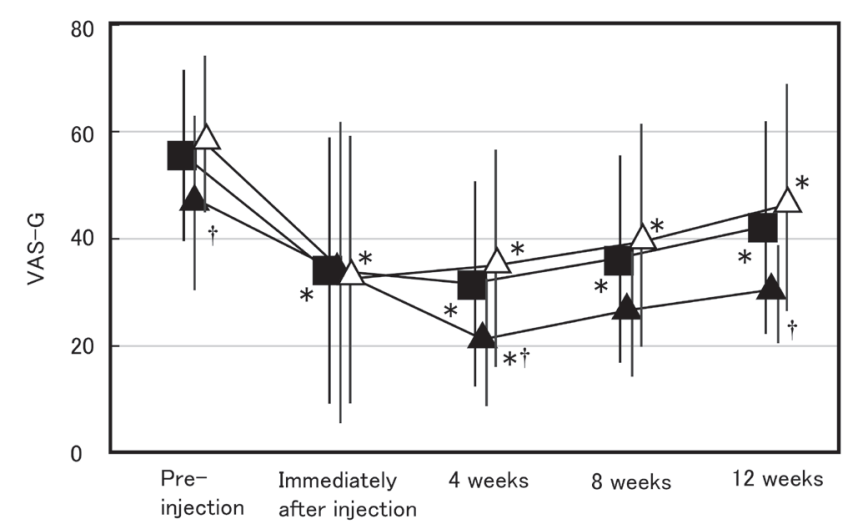

(B)

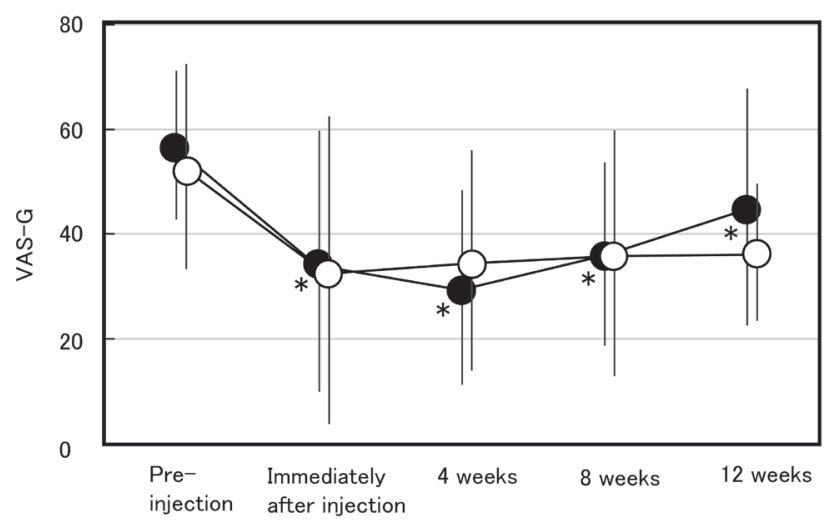

Fig. 1. Changes in visual analog scale of pain during gait (VAS-G) after the injection of Hylan G-F 20. Statistical significance was evaluated by ANOVA. (A) All cases and comparison between the mild and severe OA groups. $\mathbf{m}$, all cases ( $\mathrm{P}$ $<0.001) ; \mathbf{\Lambda}$, mild OA group $(\mathrm{P}=0.010) ; \triangle$, severe OA group $(\mathrm{P}<0.001)$. There was no time $\times$ group interaction $(\mathrm{P}=0.341)$. (B) Comparison between the dysplastic and non-dysplastic groups. $\bullet, \mathrm{CE}<20^{\circ}(\mathrm{P}<0.001) ; \circ, \mathrm{CE} \geq 20^{\circ}(\mathrm{P}=0.077)$. There was no time $\times$ group interaction $(\mathrm{P}=0.603)$. ${ }^{*}$ Significant $\mathrm{P}$ value $(\mathrm{P}<0.05)$ calculated by paired $t$-test comparing the VAS-G at each time point with those at pre-injection with Bonferroni correction (quadrupled). $\dagger$ Significant $\mathrm{P}$ value $(\mathrm{P}<0.05)$ calculated by independent $t$-test between the two groups at each time point.

(A)

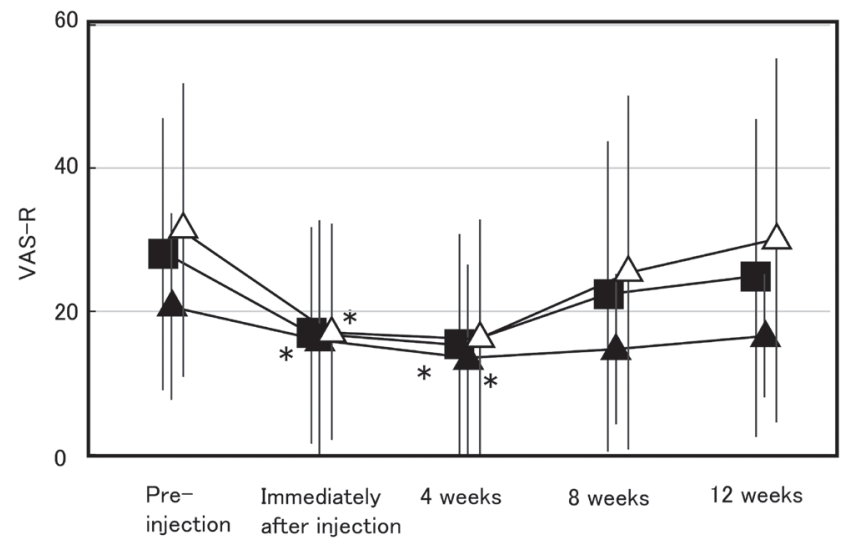

(B)

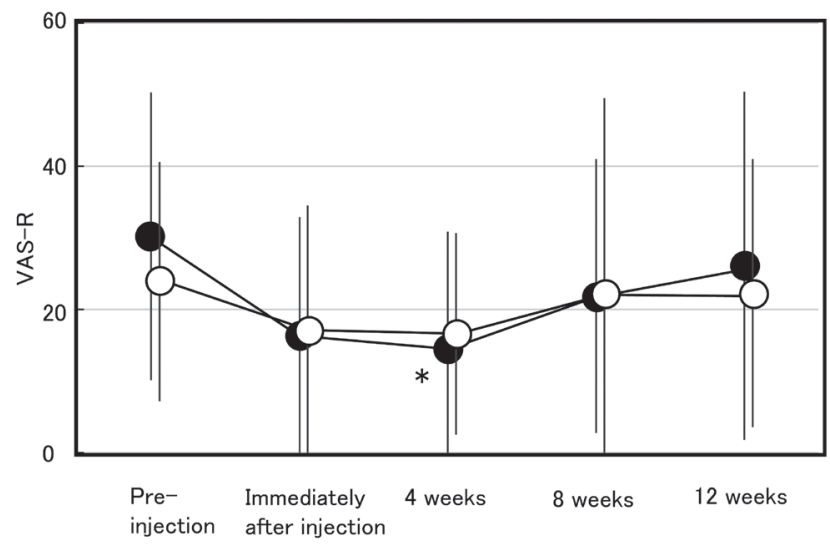

Fig. 2. Changes in visual analog scale of pain at rest (VAS-R) after the injection of Hylan G-F 20. Statistical significance was evaluated by ANOVA. (A) All cases and comparison between the mild and severe OA groups. $\mathbf{m}$, all cases $(\mathrm{P}<0.001)$; $\boldsymbol{\Lambda}$, mild OA group $(\mathrm{P}=0.010) ; \triangle$, severe $\mathrm{OA}$ group $(\mathrm{P}<0.001)$. There was no time $\times$ group interaction $(\mathrm{P}=0.351)$. (B) Comparison between the dysplastic and non-dysplastic groups. $\bullet, \mathrm{CE}<20^{\circ}(\mathrm{P}<0.001) ; \circ, \mathrm{CE} \geq 20^{\circ}(\mathrm{P}=0.638)$. There was no time $\times$ group interaction $(\mathrm{P}=0.649)$. $*$ Significant $\mathrm{P}$ value $(\mathrm{P}<0.05)$ calculated by paired $t$-test comparing the VAS-R at each time point with those at pre-injection with Bonferroni correction (quadrupled). Comparisons by independent $t$-test of the VAS-R between the mild and severe OA groups and between the dysplastic and non-dysplastic groups at each time point were not significant ( $\mathrm{P}$ $>0.05)$.

and severe OA groups at any time point. ANOVA showed that VAS-R improved in the severe OA group but not in the mild OA group. There was no time $\times$ group interaction. Pairwise $t$-test demonstrated that improvement in pain at rest was limited to within 4 weeks after injection in both groups.

Comparison of VAS-R between the dysplastic and nondysplastic groups showed that there was no statistically significant difference between the two groups at any time point. 
Table 2. Number of patients with positive signs on each pain provocation test

\begin{tabular}{lcccccccc}
\hline & FABER & P-value & FADIR & P-value & rSLR & P-value & $\begin{array}{c}\text { Tenderness at } \\
\text { Scarpa's triangle }\end{array}$ & P-value \\
\hline Pre-injection & 26 & - & 24 & - & 21 & - & 25 & - \\
Immediately after injection & 9 & $<0.001^{*}$ & 12 & $0.006^{*}$ & 12 & $0.031^{*}$ & 10 & $0.001^{*}$ \\
4 weeks & 12 & $0.009^{*}$ & 16 & 0.173 & 10 & $0.022^{*}$ & 11 & $0.005^{*}$ \\
8 weeks & 18 & 0.173 & 18 & 0.456 & 14 & 0.182 & 15 & $0.037^{*}$ \\
12 weeks & 16 & 0.106 & 19 & 1.000 & 13 & 0.108 & 17 & 0.182 \\
\hline
\end{tabular}

FABER, flexion, abduction, and external rotation; FADIR, flexion, adduction, and internal rotation; rSLR, resistive straight leg raising.

P-values were calculated using the McNemar method comparing the number of positive patients in the pain provocation test at each time period with that before injection.

*Significant.

VAS-R improved significantly after injection in the dysplastic group, but not in the non-dysplastic group. There was no time $\times$ group interaction. Pairwise $t$-tests also showed that VAS-R improved within 4 weeks in the dysplastic groups. In the non-dysplastic group, improvement in VAS-R was not observed throughout the follow-up period.

Pain provocation tests were performed at each time point (Table 2). The number of patients positive for each pain provocation test decreased after the injection, but statistical significance was not observed from 8 weeks onward for the FABER test, from 4 weeks for the FADIR test, from 8 weeks for the rSLR test, and from 12 weeks for Scarpa's triangle tenderness. The number of patients with a minimum of three positive signs on pain provocation tests remained significantly low throughout the observation period (Table 3 ).

Hip function evaluated by the JOA score was enhanced throughout the observation period (Table 4). JOA scores at each time point were higher in the mild OA group than in the severe OA group. Both the mild and severe OA groups demonstrated improvement after the injection; however, the difference was not statistically significant throughout the observation period in the mild OA group. There was no difference in JOA scores at each time point between the dysplastic and non-dysplastic groups. The JOA score increased after the injection; however, a statistical difference was not observed after 8 weeks in the non-dysplastic group.

Changes in each item of the JOA score are summarized in Table 5. The JOA-pain and JOA-ROM scores remained significantly improved until 12 weeks and 8 weeks, respectively. In contrast, there was no significant improvements in the JOA-gait and JOA-activities of daily life scores at any time point. These results indicate that the improvements in hip function mainly resulted from the improvement in pain and ROM.
ANOVA revealed that HRQoL improved after the injection for 12 weeks (Table 6). The HRQoL at each time point also improved after injection and significance was maintained for 8 weeks.

Comparison of HRQoL between the mild and severe OA groups at each time point showed that HRQoL was significantly higher in the mild OA group than in the severe OA group at 4 and 8 weeks after injection. The HRQoL improved significantly after injection in both the mild and severe OA groups, and there was no time $\times$ group interaction. Pairwise $t$-tests also showed that HRQoL was higher after injection; however, statistical significance was observed only at 4 weeks after injection in the mild OA group and at 12 weeks after injection in the severe OA group.

There was no statistical difference in HRQoL between the dysplastic and non-dysplastic groups at any time point. HRQoL improved significantly after injection in the dysplastic group; however, statistical significance was not observed in the non-dysplastic group. No time $\times$ group interaction was observed. The HRQoL at each time point after injection was higher than that before injection; however, statistical significance was observed only at 4 weeks after injection in the dysplastic group.

Eight patients requested a second injection. Among the other 21 participants, 4 patients had already tentatively scheduled THA before the study, 8 preferred THA over a second injection, and the pain in 6 had improved to the extent that they did not request either a second injection or THA. Evaluations of the effects of the second injection are summarized in Table 7. No statistical improvement was observed in VAS-G, VAS-R, JOA, or HRQoL when comparing scores before and after the second injection. However, comparison of the scores before the first injection and at 12 weeks after the second injection showed that VAS-G and HRQoL re- 
mained significantly improved.

There were no systemic adverse events or serious local complications such as hematoma, femoral nerve injury, or infection. No air embolism, which is related to air arthrography, was observed. Three of the 29 hips showed the temporal worsening of local pain (from 53.3 to 62.0 in the average VAS-G score) immediately after the injection. However, the pain had improved within $24 \mathrm{~h}$ in all three cases, and the average VAS-G score of these three cases was 34.7 at 4 weeks after the injection.

\section{DISCUSSION}

Our results demonstrated that injection of Hylan G-F 20 to the hip joint in OA patients reduced pain during gait and at rest and improved hip joint function and quality of life. The results of pain provocation tests also suggested that Hylan G-F 20 was effective in reducing hip pain induced by mechanical stress. These findings were consistent with previous results in non-Japanese populations, ${ }^{11,17,28,29)}$ suggesting that injection to the hip joint is also an effective non-operative treatment for the Japanese population.

We evaluated the effect of dysplastic hips on the results because such hips are a more common cause of OA in the Japanese population. There were no differences in VAS-G, JOA, or HRQoL scores between the dysplastic and non-dysplastic groups at any time point, which means that dysplasia did not affect the severity of symptoms. VAS-G and HRQoL were significantly improved after injection in both dysplastic and non-dysplastic groups; consequently, hip injection of Hylan G-F 20 is considered to be effective regardless of dysplasia of the hip joint.

VAS-G and HRQoL were significantly improved after injection in both the mild and severe OA groups; therefore, hip injection of Hylan G-F 20 was considered to be effective regardless of radiographic severity. The VAS-G score was lower and the JOA and HRQoL scores were higher after injection in the mild OA group; however, statistical significance did not last throughout the entire 12-week follow-up period. This may be because the pre-injection VAS-G was relatively low and the JOA and HRQoL scores were relatively high in this group, and the difference between before and after the injection may be relatively small, thereby diminishing statistical significance. Moreover, the sample sizes after grouping were small, and this may also have affected the significance.

The results of the current study indicated that hip injection of Hylan G-F 20 improved hip pain, function, and quality of life for as long as 12 weeks. However, the half-life of Hylan
G-F 20 in the knee is reportedly 8.8 days, ${ }^{30)}$ and Hylan G-F 20 persisted in only trace amounts microscopically for up to 28 days in superficial synovium and articular cartilage after injection to the knee of the goat. ${ }^{31)}$ These facts cannot explain the length of the effect ( 12 weeks) after the injection obtained in the current study only by the mechanism of the lubricating and shock-absorbing properties of Hylan G-F 20. Biological effects of HA have also been reported to explain the long-lasting effects of HA-IA, ${ }^{32)}$ and our results are consistent with this hypothesis.

Improvements in VAS-G, VAS-R, JOA, and HRQoL scores were not statistically significant after the second injection. This may be because the condition of the hips before the second injection was already improved compared to that before the first injection. Pain during gait and quality of life at 12 weeks after the second injection was improved compared to that before the first injection, indicating that the second injection was able to maintain the effect of the first injection for an additional 12 weeks.

There were no severe adverse effects after Hylan G-F 20 injection and only three minor adverse events (an increase in pain after injection). All these three cases showed improvement on the following day. The rate of minor adverse events $(10.3 \%$ /patient, $8.1 \%$ /injection) was similar to or less than that described in previous reports (10.1-20.8\%/patient, $7.1-12.8 \%$ /injection $\left.{ }^{15,17,33)}\right)$. The rate of adverse events in patients using other hyaluronic acids was reported to be similar to that of Hylan G-F 20.34) It has also been reported that the rates of adverse events were similar between placebo and HA injection groups. ${ }^{15,35)}$ No severe acute inflammatory reaction was observed after the injection in the current study. Acute local inflammatory reactions after injection of Hylan G-F 20 into the knee and the hip joint have been reported, and the possibility of a higher frequency in the hip than in the knee has been pointed out. ${ }^{10,29)}$ It is suspected that chemically cross-linked HA molecules are the cause of arthritis ${ }^{36}$ ) or that the accumulation of HA results in sensitization ${ }^{37)}$; nonetheless, there are reports that these reactions can occur after the first HA injection ${ }^{38)}$ or after injection of HAs other than Hylan G-F 20, and the cause of this has not yet been clarified. ${ }^{39)}$ Considering these reports, it is considered that Hylan G-F 20 can be used safely, but it must be used with caution because any acute inflammatory reaction may require differentiation from septic arthritis. Data from the national registry of Iceland indicate that the infection rate after hip injection is estimated to be $0.037 \%{ }^{40 \text { ) }}$

There are some limitations to this study. First, the sample size was relatively small. Furthermore, the effect of Hylan 
Table 3. Number of patients with less than three positive signs and three or more positive signs in pain provocation tests at each time point

\begin{tabular}{lrrr}
\hline & $<3$ & $\geq 3$ & P-value \\
\hline Pre-injection & 3 & 25 & - \\
Immediately after injection & 18 & 10 & $0.001^{*}$ \\
4 weeks & 21 & 7 & $<0.001^{*}$ \\
8 weeks & 17 & 11 & $0.002^{*}$ \\
12 weeks & 15 & 13 & $0.006^{*}$ \\
\hline
\end{tabular}

P-values were calculated using the McNemar method with Bonferroni correction (quadrupled) comparing the number of positive pain provocation tests in each patient before injection and each time period after injection.

*Significant.

Table 4. Changes of JOA scores after the intra-articular injection

\begin{tabular}{|c|c|c|c|c|c|c|c|}
\hline & $\begin{array}{c}\text { All cases } \\
n=29 \\
\left(P-\text { value }^{1)}\right)\end{array}$ & $\begin{array}{c}\text { Mild OA } \\
\text { n=9 } \\
\left(\mathrm{P}-\text { value }^{1)}\right)\end{array}$ & $\begin{array}{c}\text { Severe OA } \\
\quad n=20 \\
\left(P-\text { value }^{1)}\right)\end{array}$ & P-value ${ }^{2)}$ & $\begin{array}{c}\mathrm{CE}<20^{\circ} \\
\mathrm{n}=19 \\
\left(\mathrm{P}-\text { value }^{1)}\right)\end{array}$ & $\begin{array}{c}\mathrm{CE} \geq 20^{\circ} \\
n=10 \\
\left(\mathrm{P} \text {-value }{ }^{1)}\right)\end{array}$ & P-value ${ }^{2)}$ \\
\hline Pre-injection & $66.2 \pm 14.8$ & $75.1 \pm 17.7$ & $62.3 \pm 11.6$ & $0.036^{*}$ & $65.3 \pm 13.7$ & $68.0 \pm 17.2$ & 0.597 \\
\hline 4 weeks & $\begin{array}{c}74.7 \pm 13.3 \\
\left(<0.001^{*}\right)\end{array}$ & $\begin{array}{c}81.2 \pm 10.9 \\
(0.837)\end{array}$ & $\begin{array}{c}71.8 \pm 13.4 \\
\left(<0.001^{*}\right)\end{array}$ & 0.053 & $\begin{array}{c}73.9 \pm 13.6 \\
\left(0.017^{*}\right)\end{array}$ & $\begin{array}{c}76.1 \pm 13.2 \\
\left(0.041^{*}\right)\end{array}$ & 0.597 \\
\hline 8 weeks & $\begin{array}{c}74.8 \pm 12.0 \\
(0.002 *)\end{array}$ & $\begin{array}{c}81.3 \pm 10.2 \\
(1.000)\end{array}$ & $\begin{array}{c}71.9 \pm 11.8 \\
\left(0.002^{*}\right)\end{array}$ & $0.032 *$ & $\begin{array}{c}74.7 \pm 12.2 \\
\left(0.009^{*}\right)\end{array}$ & $\begin{array}{c}75.0 \pm 12.2 \\
(0.229)\end{array}$ & 0.963 \\
\hline 12 weeks & $\begin{array}{c}71.8 \pm 13.9 \\
\left(0.024^{*}\right) \\
\end{array}$ & $\begin{array}{c}78.2 \pm 12.8 \\
(1.000) \\
\end{array}$ & $\begin{array}{c}68.7 \pm 13.6 \\
\left(0.008^{*}\right) \\
\end{array}$ & 0.133 & $\begin{array}{c}71.5 \pm 14.1 \\
\left(0.047^{*}\right)\end{array}$ & $\begin{array}{c}72.2 \pm 14.2 \\
(0.468)\end{array}$ & 0.848 \\
\hline
\end{tabular}

JOA, the Japanese Orthopaedic Association.

${ }^{1}$ Figures in parentheses are P-values calculated using the Wilcoxon rank-sum test comparing the values at each time period with that before injection. P-values were tripled according to the Bonferroni correction.

${ }^{2} \mathrm{P}$-values were calculated using the Mann-Whitney test comparing JOA scores between two groups at each time period.

* Significant.

Table 5. Changes of each item of JOA scores after the intra-articular injection

\begin{tabular}{lcccccccc}
\hline & Pain & P-value $^{1)}$ & ROM & P-value & Gait & P-value $^{1)}$ & ADL & P-value \\
\hline Pre-injection & $16.6 \pm 9.4$ & - & $16.1 \pm 4.2$ & - & $15.8 \pm 3.9$ & - & $17.5 \pm 2.9$ & - \\
4 weeks & $23.3 \pm 8.7$ & $0.004^{*}$ & $17.0 \pm 3.3$ & $0.030^{*}$ & $16.9 \pm 2.2$ & 0.206 & $18.1 \pm 2.4$ & 0.120 \\
8 weeks & $22.8 \pm 8.8$ & $0.007^{*}$ & $17.0 \pm 3.3$ & $0.016^{*}$ & $17.0 \pm 2.1$ & 0.327 & $17.9 \pm 2.4$ & 1.000 \\
12 weeks & $21.1 \pm 9.5$ & $0.014^{*}$ & $16.1 \pm 4.1$ & 1.000 & $16.1 \pm 3.0$ & 1.000 & $17.8 \pm 2.5$ & 1.000 \\
\hline
\end{tabular}

ROM, range of motion; ADL, activities of daily life.

${ }^{1} \mathrm{P}$-values were calculated using the Wilcoxon rank-sum test comparing the values at each time period with that at preinjection.

*Significant.

G-F 20 beyond 12 weeks was not investigated. Therefore, future studies with a larger number of patients and a longer period of observation are necessary to confirm the current results. Another limitation is that, for ethical reasons, our study was not a randomized controlled trial with a placebo group. A meta-analysis of HA injection into the knee showed that the improvement of pain and function compared to the placebo group depended on the type of HA, and that Hylan G-F 20 did result in such improvements. ${ }^{41)}$ Whereas most hip injection studies do not have a placebo group, ${ }^{10-15)}$ there are three studies of hip injection that compare the HA group with a placebo group and show no difference between them. ${ }^{42)}$ However, Brander et al. evaluated the effects of HA-IA using the Western Ontario McMaster Universities Osteoarthritis Index, in which the pain score is classified into five levels and subtle differences at the same level could be neglected. ${ }^{15}$ ) The other two studies compared pain using the VAS score; however, the HA used was of low molecular weight. ${ }^{35,42)}$ 
Table 6. Health-related quality of life (HRQoL) scores at each time period

\begin{tabular}{|c|c|c|c|c|c|c|c|}
\hline & $\begin{array}{c}\text { All cases } \\
n=29 \\
\left(P-\text { value }^{1)}\right)\end{array}$ & $\begin{array}{c}\text { Mild OA } \\
n=9 \\
\left.\text { (P-value }^{1)}\right)\end{array}$ & $\begin{array}{c}\text { Severe OA } \\
n=20 \\
\left(\mathrm{P}-\text { value }^{1)}\right)\end{array}$ & P-value ${ }^{3)}$ & $\begin{array}{c}\mathrm{CE}<20^{\circ} \\
\mathrm{n}=19 \\
\left(\mathrm{P}-\text { value }^{1)}\right)\end{array}$ & $\begin{array}{c}\mathrm{CE} \geq 20^{\circ} \\
\mathrm{n}=10 \\
\left(\mathrm{P}-\text {-value }^{1)}\right)\end{array}$ & P-value ${ }^{3)}$ \\
\hline Pre-injection & $0.58 \pm 0.12$ & $0.60 \pm 0.12$ & $0.57 \pm 0.13$ & 0.583 & $0.57 \pm 0.14$ & $0.58 \pm 0.09$ & 0.946 \\
\hline 4 weeks & $\begin{array}{l}0.66 \pm 0.10 \\
\left(0.002^{*}\right)\end{array}$ & $\begin{array}{c}0.72 \pm 0.14 \\
\left(0.010^{*}\right)\end{array}$ & $\begin{array}{c}0.63 \pm 0.06 \\
(0.089)\end{array}$ & $0.029^{*}$ & $\begin{array}{c}0.67 \pm 0.11 \\
\left(0.018^{*}\right)\end{array}$ & $\begin{array}{c}0.64 \pm 0.13 \\
(0.144)\end{array}$ & 0.541 \\
\hline 8 weeks & $\begin{array}{c}0.65 \pm 0.11 \\
\left(0.019^{*}\right)\end{array}$ & $\begin{array}{l}0.71 \pm 0.14 \\
(0.126)\end{array}$ & $\begin{array}{c}0.62 \pm 0.08 \\
(0.225)\end{array}$ & $0.040^{*}$ & $\begin{array}{c}0.64 \pm 0.09 \\
(0.168)\end{array}$ & $\begin{array}{c}0.67 \pm 0.14 \\
(0.186)\end{array}$ & 0.473 \\
\hline 12 weeks & $\begin{array}{c}0.65 \pm 0.14 \\
\quad(0.106)\end{array}$ & $\begin{array}{c}0.68 \pm 0.15 \\
(0.234)\end{array}$ & $\begin{array}{c}0.64 \pm 0.13 \\
\left(0.046^{*}\right)\end{array}$ & 0.398 & $\begin{array}{c}0.63 \pm 0.11 \\
(0.100)\end{array}$ & $\begin{array}{c}0.69 \pm 0.26 \\
(0.097)\end{array}$ & 0.277 \\
\hline P-value ANOVA ${ }^{2)}$ & $<0.001^{*}$ & $0.030 *$ & $0.030^{*}$ & & $0.006^{*}$ & 0.056 & \\
\hline $\begin{array}{l}\text { Test for Group } \times \\
\text { Time Interaction }\end{array}$ & & \multicolumn{2}{|c|}{ Severity; 0.512} & & \multicolumn{2}{|c|}{ Dysplasia; 0.309} & \\
\hline
\end{tabular}

ANOVA, analysis of variance.

${ }^{1}$ Numbers in parentheses are P-values, with Bonferroni correction (tripled), calculated by paired $t$-test comparing the VAS scores at each time period with those at pre-injection.

${ }^{2} \mathrm{P}$-values calculated using ANOVA with Huynh-Feldt correction comparing the VAS scores before and after injection.

${ }^{3} \mathrm{P}$-values were calculated by independent $t$-test between two groups at each time period.

${ }^{4} \mathrm{P}$ value for the group $\times$ time interaction.

*Significant.

Table 7. Results of second injection

\begin{tabular}{lcccc}
\hline & VAS-G & VAS-R & JOA $^{1)}$ & HRQoL $^{1)}$ \\
\hline Before first injection & $49.0 \pm 12.0$ & $22.6 \pm 9.7$ & $74.3 \pm 12.1$ & $0.64 \pm 0.10$ \\
Before second injection & $39.7 \pm 17.5$ & $23.8 \pm 22.2$ & $74.3 \pm 6.5$ & $0.67 \pm 0.07$ \\
4 weeks & $46.1 \pm 27.8$ & $32.5 \pm 22.1$ & $70.0 \pm 18.7$ & $0.70 \pm 0.22$ \\
& $(1.000)$ & $(1.000)$ & $(1.000)$ & $(1.000)$ \\
8 weeks & $38.6 \pm 14.6$ & $26.3 \pm 14.7$ & $80.8 \pm 4.7$ & $0.70 \pm 0.15$ \\
& $(1.000)$ & $(1.000)$ & $(0.278)$ & $(1.000)$ \\
12 weeks & $33.8 \pm 0.14$ & $22.8 \pm 18.8$ & $81.9 \pm 11.1$ & $0.73 \pm 0.18$ \\
P-value ANOVA & $(1.000)$ & $(1.000)$ & $(0.176)$ & $(0.735)$ \\
P-value (before first injection to & 0.653 & 0.560 & - & 0.352 \\
second 12 weeks) & $0.032^{*}$ & 0.493 & 0.141 & $0.048^{*}$ \\
\hline
\end{tabular}

HRQoL, health-related quality of life.

${ }^{1} \mathrm{P}$-values (shown in parentheses) were calculated by paired $t$-test with Bonferroni correction (tripled) comparing the values at each time period with that before the second injection.

${ }^{2} \mathrm{P}$-values (shown in parentheses) were calculated by Wilcoxon rank-sum test with Bonferroni correction (tripled) comparing the JOA scores at each time period with those before the second injection.

${ }^{3}$ P-values calculated by ANOVA with Huynh-Feldt correction comparing the values before and after injection.

*Significant.

The half-life of low-molecular-weight HA in rabbit knees is reportedly $17-20 \mathrm{~h}$, and it disappears completely within 3 days. ${ }^{30,43)}$ Consequently, these previous three studies do not necessarily refute the findings of the current study. Reports with placebo groups are still rare, and, therefore, future studies with a placebo group are desirable. In the present study, patients were allowed to continue using routine analgesic agents, and this fact could be another limitation. However, our patients were instructed not to change analgesics with regard to the type and dose in the 8 weeks before the injection. Therefore, we believe that the effect of hip injection was evaluated adequately. Uncertainty in the hip joint injection may also be considered a limitation. To minimize this limitation, we applied hip injections using an air arthrogram 
method to confirm the needle position. In a previous study, air arthrograms were used to confirm the needle position in the hip joint, ${ }^{44)}$ and the accuracy of the needle position confirmed using a contrast agent arthrogram was reported as $100 \% .{ }^{21)}$ The adverse effects associated with contrast agents include pain, swelling, and an allergic reaction, including anaphylaxis. We used air arthrography to avoid these adverse events as well as any influence on the effect of HA.

In this study, Hylan G-F 20 injection to the hip joint was effective in reducing pain during gait and in improving hip joint function and quality of life for 12 weeks. After a second injection of Hylan G-F 20, the effects lasted for a minimum of a further 12 weeks. Consequently, Hylan G-F 20 can be used as a non-operative treatment for hip OA in the Japanese population. Further research with a larger comparative design is warranted.

\section{ACKNOWLEDGMENTS}

We thank Drs. Kazumasa Miyatake and Masanobu Hirao for assistance with study recruitment and clinical data collection.

\section{CONFLICTS OF INTEREST}

The authors declare that there is no conflict of interest regarding the publication of this article.

\section{REFERENCES}

1. Aresti N, Kassam J, Nicholas N, Achan P: Hip osteoarthritis. BMJ 2016;354:i3405. DOI:10.1136/bmj.i3405, PMID:27383835

2. Jingushi S, Ohfuji S, Sofue M, Hirota Y, Itoman M, Matsumoto T, Hamada Y, Shindo H, Takatori Y, Yamada H, Yasunaga Y, Ito H, Mori S, Owan I, Fujii G, Ohashi H, Iwamoto Y, Miyanishi K, Iga T, Takahira N, Sugimori T, Sugiyama H, Okano K, Karita T, Ando K, Hamaki T, Hirayama T, Iwata K, Nakasone S, Matsuura M, Mawatari T: Multiinstitutional epidemiological study regarding osteoarthritis of the hip in Japan. J Orthop Sci 2010;15:626-631. DOI:10.1007/s00776-0101507-8, PMID:20953923
3. Reijman M, Bierma-Zeinstra SM, Pols HA, Koes BW, Stricker BH, Hazes JM: Is there an association between the use of different types of nonsteroidal antiinflammatory drugs and radiologic progression of osteoarthritis?: The Rotterdam Study. Arthritis Rheum 2005;52:31373142. DOI:10.1002/art.21357, PMID:16200593

4. Busse P, Vater C, Stiehler M, Nowotny J, Kasten $\mathrm{P}$, Bretschneider $\mathrm{H}$, Goodman SB, Gelinsky M, Zwingenberger S: Cytotoxicity of drugs injected into joints in orthopaedics. Bone Joint Res 2019;8:41-48. DOI:10.1302/2046-3758.82.BJR-2018-0099.R1, PMID:30915209

5. Mathews CJ, Weston VC, Jones A, Field M, Coakley G: Bacterial septic arthritis in adults. Lancet 2010;375:846-855. DOI:10.1016/S0140-6736(09)615956, PMID:20206778

6. Benke M, Shaffer B: Viscosupplementation treatment of arthritis pain. Curr Pain Headache Rep 2009;13:440-446. DOI:10.1007/s11916-009-0072-3, PMID:19889285

7. Bannuru RR, Osani MC, Vaysbrot EE, Arden NK, Bennell K, Bierma-Zeinstra SM, Kraus VB, Lohmander LS, Abbott JH, Bhandari M, Blanco FJ, Espinosa R, Haugen IK, Lin J, Mandl LA, Moilanen E, Nakamura N, Snyder-Mackler L, Trojian T, Underwood M, McAlindon TE: OARSI guidelines for the non-surgical management of knee, hip, and polyarticular osteoarthritis. Osteoarthritis Cartilage 2019;27:1578-1589. DOI:10.1016/j.joca.2019.06.011, PMID:31278997

8. Tsumura H: An expert consensus guideline for controlling osteoarthritis of the knee based on OARSI recommendations. [in Japanese]. Nippon Naika Gakkai Zasshi 2017;106:75-83. DOI:10.2169/naika.106.75

9. Jevsevar DS: Treatment of osteoarthritis of the knee: evidence-based guideline, 2nd edition. J Am Acad Orthop Surg 2013; 21: 571-576.

10. Conrozier T, Vignon E: Is there evidence to support the inclusion of viscosupplementation in the treatment paradigm for patients with hip osteoarthritis? Clin Exp Rheumatol 2005;23:711-716. PMID:16173254

11. Caglar-Yagci H, Unsal S, Yagci I, Dulgeroglu D, Ozel S: Safety and efficacy of ultrasound-guided intraarticular hylan G-F 20 injection in osteoarthritis of the hip: a pilot study. Rheumatol Int 2005;25:341-344. DOI:10.1007/s00296-004-0441-5, PMID:15004721 
12. Rennesson-Rey B, Rat AC, Chary-Valckenaere I, Bettembourg-Brault I, Juge N, Dintinger H, Pourel J, Loeuille D: Does joint effusion influence the clinical response to a single Hylan GF-20 injection for hip osteoarthritis? Joint Bone Spine 2008;75:182-188. DOI:10.1016/j.jbspin.2007.05.017, PMID:18314368

13. De Lucia O, Pierannunzii LM, Pregnolato F, Verduci E, Crotti C, Valcamonica E, Pisoni L, Comi D, Lonati PA, Meroni PL, Murgo A: Effectiveness and tolerability of repeated courses of viscosupplementation in symptomatic hip osteoarthritis: a retrospective observational cohort study of high molecular weight vs. medium molecular weight hyaluronic acid vs. no viscosupplementation. Front Pharmacol 2019;10:1007. DOI:10.3389/fphar.2019.01007, PMID:31616292

14. Maheu E, Avouac B, Dreiser RL, Bardin T: A single intra-articular injection of $2.0 \%$ non-chemically modified sodium hyaluronate vs $0.8 \%$ hylan G-F 20 in the treatment of symptomatic knee osteoarthritis: a 6-month, multicenter, randomized, controlled non-inferiority trial. PLoS One 2019;14:e0226007. DOI:10.1371/journal.pone.0226007, PMID:31821355

15. Brander V, Skrepnik N, Petrella RJ, Jiang GL, Accomando B, Vardanyan A: Evaluating the use of intraarticular injections as a treatment for painful hip osteoarthritis: a randomized, double-blind, multicenter, parallel-group study comparing a single 6-mL injection of hylan G-F 20 with saline. Osteoarthritis Cartilage 2019;27:59-70. DOI:10.1016/j.joca.2018.08.018, PMID:30223023

16. Migliore A, Frediani B, Gigliucci G, Foti C, Crimaldi S, De Lucia O, Iolascon G: Efficacy of a single intraarticular HYMOVIS ONE injection for managing symptomatic hip osteoarthritis: a 12-month follow-up retrospective analysis of the ANTIAGE register data. Orthop Res Rev 2020;12:19-26. DOI:10.2147/ORR. S239355, PMID:32184679

17. Conrozier T, Bertin P, Mathieu P, Charlot J, Bailleul F, Treves R, Vignon E, Chevalier X: Intra-articular injections of hylan G-F 20 in patients with symptomatic hip osteoarthritis: an open-label, multicentre, pilot study. Clin Exp Rheumatol 2003;21:605-610. PMID:14611109
18. Ohfuji S, Jingushi S, Kondo K, Sofue M, Itoman M, Matsumoto T, Hamada Y, Shindo H, Takatori Y, Yamada H, Yasunaga Y, Ito H, Mori S, Owan I, Fujii G, Ohashi H, Takahashi S, Hirota Y: Factors associated with diagnostic stage of hip osteoarthritis due to acetabular dysplasia among Japanese female patients: a cross-sectional study. BMC Musculoskelet Disord 2016;17:320. DOI:10.1186/s12891-016-1179-4, PMID:27484820

19. Ueno R: Staging of osteoarthritis of the hip joint according to the roentgenographic findings [in Japanese]. J Jpn Orthop Assoc 1971;45:826-828.

20. Takatori Y, Ito K, Sofue M, Hirota Y, Itoman M, Matsumoto T, Hamada Y, Shindo H, Yamada H, Yasunaga Y, Ito H, Mori S, Owan I, Fujii G, Ohashi H, Mawatari T, Iga T, Takahira N, Sugimori T, Sugiyama H, Okano K, Karita T, Ando K, Hamaki T, Hirayama T, Iwata $\mathrm{K}$, Matsuura M, Jingushi S, Investigation Group into Coxarthrosis and Acetabular Dysplasia in Japan: Analysis of interobserver reliability for radiographic staging of coxarthrosis and indexes of acetabular dysplasia: a preliminary study. J Orthop Sci 2010;15:14-19. DOI:10.1007/s00776-009-1412-1, PMID:20151246

21. Shahid M, Shyamsundar S, Bali N, McBryde C, O'Hara J, Bache E: Efficacy of using an air arthrogram for EUA and injection of the hip joint in adults. J Orthop 2014;11:132-135. DOI:10.1016/j.jor.2014.06.011, PMID:25264407

22. Koyano G, Jinno T, Koga D, Hoshino C, Muneta T, Okawa A: Is closed suction drainage effective in early recovery of hip joint function? Comparative evaluation in one-stage bilateral total hip arthroplasty. J Arthroplasty 2015;30:74-78. DOI:10.1016/j.arth.2014.08.007, PMID:25216791

23. Koyano G, Jinno T, Koga D, Yamauchi Y, Muneta T, Okawa A: Comparison of bone remodeling between an anatomic short stem and a straight stem in 1-stage bilateral total hip arthroplasty. J Arthroplasty 2017;32:594-600. DOI:10.1016/j.arth.2016.07.016, PMID:27554784

24. Wilson JJ, Furukawa M: Evaluation of the patient with hip pain. Am Fam Physician 2014;89:27-34. PMID:24444505

25. Bierma-Zeinstra SM, Oster JD, Bernsen RM, Verhaar JA, Ginai AZ, Bohnen AM: Joint space narrowing and relationship with symptoms and signs in adults consulting for hip pain in primary care. J Rheumatol 2002;29:1713-1718. PMID:12180735 
26. Tsuchiya A, Ikeda S, Ikegami N, Nishimura S, Sakai I, Fukuda T, Hamashima C, Hisashige A, Tamura M: Estimating an EQ-5D population value set: the case of Japan. Health Econ 2002;11:341-353. DOI:10.1002/ hec.673, PMID:12007165

27. Kanda Y: Investigation of the freely available easyto-use software 'EZR' for medical statistics. Bone Marrow Transplant 2013;48:452-458. DOI:10.1038/ bmt.2012.244, PMID:23208313

28. Vad VB, Sakalkale D, Sculco TP, Wickiewicz TL: Role of hylan G-F 20 in treatment of osteoarthritis of the hip joint. Arch Phys Med Rehabil 2003;84:1224-1226. DOI:10.1016/S0003-9993(03)00140-0, PMID:12917864

29. Brocq O, Tran G, Breuil V, Grisot C, Flory P, Euller-Ziegler L: Hip osteoarthritis: short-term efficacy and safety of viscosupplementation by hylan G-F 20. An open-label study in 22 patients. Joint Bone Spine 2002;69:388-391. DOI:10.1016/S1297319X(02)00416-5, PMID:12184436

30. Brandt KD, Smith GN Jr, Simon LS: Intraarticular injection of hyaluronan as treatment for knee osteoarthritis: what is the evidence? Arthritis Rheum 2000;43:1192-1203. DOI:10.1002/15290131(200006)43:6<1192::AID-ANR2>3.0.CO;2-L, PMID:10857778

31. Jackson DW, Simon TM: Intra-articular distribution and residence time of Hylan A and B: a study in the goat knee. Osteoarthritis Cartilage 2006;14:1248-1257. DOI:10.1016/j.joca.2006.05.015, PMID:16822684

32. Webb D, Naidoo P: Viscosupplementation for knee osteoarthritis: a focus on Hylan G-F 20. Orthop Res Rev 2018;10:73-81. DOI:10.2147/ORR.S174649, PMID:30774462

33. Migliore A, Tormenta S, Massafra U, Bizzi E, Iannessi F, Alimonti A, Granata M: Intra-articular administration of hylan G-F 20 in patients with symptomatic hip osteoarthritis: tolerability and effectiveness in a large cohort study in clinical practice. Curr Med Res Opin 2008;24:1309-1316. DOI:10.1185/030079908X291930, PMID:18373891

34. Migliore A, Giovannangeli F, Granata M, Laganà B: Hylan G-F 20: review of its safety and efficacy in the management of joint pain in osteoarthritis. Clin Med Insights Arthritis Musculoskelet Disord 2010;3:55-68. DOI:10.1177/117954411000300001, PMID:21151854
35. Richette $\mathrm{P}$, Ravaud $\mathrm{P}$, Conrozier T, Euller-Ziegler L, Mazières B, Maugars Y, Mulleman D, Clerson P, Chevalier X: Effect of hyaluronic acid in symptomatic hip osteoarthritis: a multicenter, randomized, placebocontrolled trial. Arthritis Rheum 2009;60:824-830. DOI:10.1002/art.24301, PMID:19248105

36. Reichenbach S, Blank S, Rutjes AW, Shang A, King EA, Dieppe PA, Jüni P, Trelle S: Hylan versus hyaluronic acid for osteoarthritis of the knee: a systematic review and meta-analysis. Arthritis Rheum 2007;57:1410 1418. DOI:10.1002/art.23103, PMID:18050181

37. Leopold SS, Warme WJ, Pettis PD, Shott S: Increased frequency of acute local reaction to intra-articular hylan GF-20 (Synvisc) in patients receiving more than one course of treatment. J Bone Joint Surg Am 2002;84:1619-1623. DOI:10.2106/00004623200209000-00015, PMID:12208919

38. Aydin M, Arikan M, Toğral G, Varış O, Aydin G: Viscosupplementation of the knee: three cases of acute pseudoseptic arthritis with painful and irritating complications and a literature review. Eur J Rheumatol 2017;4:59-62. DOI:10.5152/eurjrheum.2016.15075, PMID:28293455

39. Ong KL, Runa M, Xiao Z, Ngai W, Lau E, Altman RD: Severe acute localized reactions following intra-articular hyaluronic acid injections in knee osteoarthritis. Cartilage 2020; online ahead of print.

40. Geirsson AJ, Statkevicius S, Víkingsson A: Septic arthritis in Iceland 1990-2002: increasing incidence due to iatrogenic infections. Ann Rheum Dis 2007;67:638643. DOI:10.1136/ard.2007.077131, PMID:17901088

41. Bellamy N, Campbell J, Welch V, Gee TL, Bourne R, Wells GA: Viscosupplementation for the treatment of osteoarthritis of the knee. Cochrane Database Syst Rev 2006; 2006.

42. Gazendam A, Ekhtiari S, Bozzo A, Phillips M, Bhandari $\mathrm{M}$ : Intra-articular saline injection is as effective as corticosteroids, platelet-rich plasma and hyaluronic acid for hip osteoarthritis pain: a systematic review and network meta-analysis of randomised controlled trials. Br J Sports Med 2021;55:256-261. DOI:10.1136/ bjsports-2020-102179, PMID:32829298

43. Adant Interview form [in Japanese]. https://www.info. pmda.go.jp/go/interview/1/780009_3999408G1301_1_ 1F.pdf.

44. Awad A, Reynolds PM, Ashworth M: Air as contrast media for hip arthrogram. Ann R Coll Surg Engl 2017;99:662. DOI:10.1308/rcsann.2017.0061, PMID:29022804 